Journal for ImmunoTherapy of Cancer

\title{
Reintroduction of immune-checkpoint inhibitors after immune-related meningitis: a case series of melanoma patients
}

\author{
Stefania Cuzzubbo (D) , ,2 Pauline Tetu, ${ }^{3,4}$ Sarah Guegan, ${ }^{5,6}$ Renata Ursu, ${ }^{2}$ \\ Catherine Belin, ${ }^{2}$ Lila Sirven Villaros, ${ }^{1,2}$ Julie Mazoyer, ${ }^{2}$ Coralie Lheure, ${ }^{7}$ \\ Celeste Lebbe, ${ }^{3,4}$ Barouyr Baroudjian, ${ }^{3}$ Antoine F Carpentier ${ }^{1,2}$
}

To cite: Cuzzubbo S, Tetu P, Guegan S, et al. Reintroduction of immune-checkpoint inhibitors after immune-related meningitis: a case series of melanoma patients. Journal for ImmunoTherapy of Cancer 2020;8:e001034. doi:10.1136/ jitc-2020-001034

Accepted 18 June 2020

Check for updates

(C) Author(s) (or their employer(s)) 2020. Re-use permitted under CC BY-NC. No commercial re-use. See rights and permissions. Published by BMJ.

${ }^{1}$ Université de Paris, Paris, France

${ }^{2}$ Service de Neurologie, Assistance Publique-Hôpitaux de Paris (AP-HP), Hôpital Saint Louis, Paris, France

${ }^{3}$ Service de Dermatologie, Assistance Publique-Hôpitaux de Paris (AP-HP), Hôpital Saint-

Louis, Paris, France

${ }^{4}$ Université de Paris, INSERM

U976, Paris, France

${ }^{5}$ Université de Paris, INSERM U1016, Paris, France

${ }^{6}$ Service de Dermatologie, Assistance Publique-Hôpitaux de Paris (AP-HP), Hôpital Cochin, Paris, France

${ }^{7}$ Service de Dermatologie, Assistance Publique-Hôpitaux de Paris (AP-HP), Hôpital BichatClaude-Bernard, Paris, France

Correspondence to

Dr Stefania Cuzzubbo;

stefania.cuzzubbo@inserm.fr

\section{ABSTRACT}

Immune-checkpoint inhibitors (ICls) targeting cytotoxic T lymphocyte-associated antigen-4 and programmed cell death ligand-1) are associated with several immune-related neurological disorders. Cases of meningitis related to ICls are poorly described in literature and probably underestimated. Several guidelines are available for the acute management of these adverse events, but the safety of resuming ICls in these patients remains unclear. We conducted a retrospective case series of immune-related meningitis associated with ICls that occurred between October 12015 and October 312019 in two centers: Saint-Louis and Cochin hospitals, Paris, France. Diagnosis was defined by a (1) high count of lymphocytes (>8 cells $/ \mathrm{mm} 3$ ) and/or high level of proteins $(>0.45 \mathrm{~g} / \mathrm{L})$ without bacteria/virus or tumor cells detection, in cerebrospinal fluid and (2) normal brain and spine imaging. Patients were followed-up for at least 6 months from the meningitis onset. Seven cases of immune-related meningitis are here reported. Median delay of meningitis occurrence after ICls onset was 9 days. Steroid treatment was introduced in four patients at a dose of $1 \mathrm{mg} / \mathrm{kg}$ (prednisone), allowing a complete recovery within 2 weeks. The other three patients spontaneously improved within 3 weeks. Given the favorable outcome, ICls were reintroduced in all patients. The rechallenge was well tolerated and no patients experienced meningitis recurrence. In conclusion, in our series, the clinica course was favorable and steroids were not always required. Resuming ICls in these patients appeared safe and can thus be considered in case of isolated meningitis. However, a careful analysis of the risk/benefit ratio should be done on a case-by-case basis.

\section{INTRODUCTION}

Immune-checkpoint inhibitors (ICIs) targeting cytotoxic T-lymphocyte-associated antigen-4 (CTLA-4), programmed cell death-1 (PD-1) and PD ligand 1 are today a standard of care in the treatment of several cancers. Initially approved for unresectable metastatic melanoma and non-small cell lung cancer, ICIs are now increasingly used to treat a high variety of solid-organ and hematological cancers. They are nevertheless associated with several immune-related (ir) disorders that can potentially involve every organ or system but gastrointestinal, dermatological, hepatic, endocrine and pulmonary toxicities predominate. ${ }^{1}$ Neurological ir adverse events (irAEs-N) are rare, with an overall incidence of $3.8 \%$ for anti-CTLA4 antibodies, $6.1 \%$ for anti-PD1 antibodies and $12.0 \%$ for the combination of them. However, the incidence of severe irAEs- $\mathrm{N}$ is below $1 \%$ for all types of treatment. Although rare irAEs-N require prompt recognition and treatment to avoid substantial morbidity. ${ }^{23}$ Several guidelines are available for the acute management of irAEs, ${ }^{4}$ but their long-term management is less standardized. Specifically, no clear data are available on the safety of resuming ICIs after an irAE. Some studies reported a $40 \%-60 \%$ rate of recurrence of the specific or distinct $\mathrm{AE}$ after the reintroduction of ICIs. ${ }^{5-8}$ As a consequence, only few patients with irAEs-N resume ICI treatment in current practice because of life-threatening risk related to neurological syndromes.

Given the benefits of ICI therapy in patients with cancer, additional research is necessary to guide clinicians in practical decisions. Considering the heterogeneity of irAEs, even within neurological irAEs, recommendations for resuming ICIs should be specifically defined for each type of them. Herein, we report a retrospective series of seven consecutive patients who developed ir-meningitis with the aim of defining the long-term management and exploring the safety of ICIs reintroduction in these patients.

\section{METHODS}

We collected the cases of ir-meningitis associated with ICIs in adult melanoma patients of Saint-Louis and Cochin hospitals, Paris, between October 12015 and October 31 
Table 1 Demographic and clinic characteristics of patients

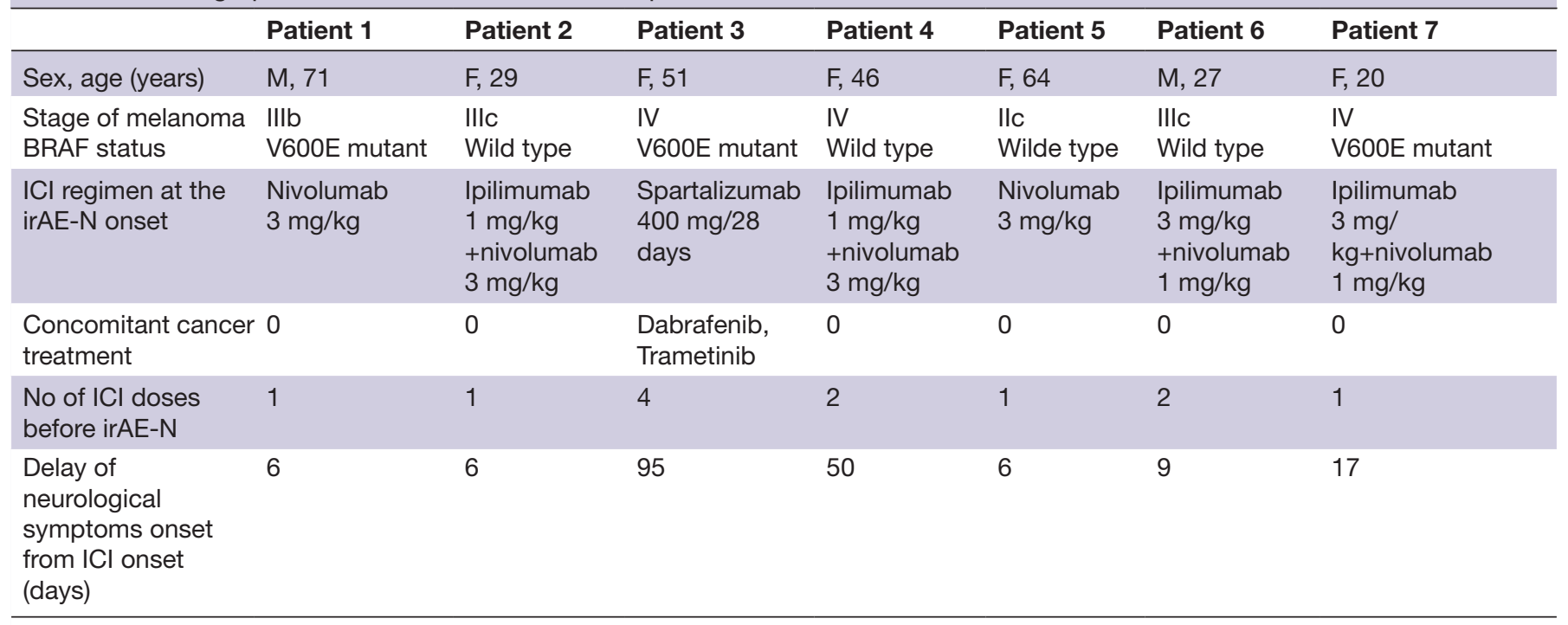

F, female; ICl, immune-checkpoint inhibitor; irAE-N, neurological immune-related adverse event; $\mathrm{M}$, male.

2019. Saint-Louis patients were registered in MelBase, a French clinical database with biobank dedicated to the prospective follow-up of adult patients with advanced melanoma. MelBase protocol was registered in the NIH clinical trials database (NCT02828202). Written informed consent was obtained from all patients.

Diagnosis was defined by the association of (1) a clinical pattern compatible with meningitis; (2) >8 lymphocytes/ $\mathrm{mm}^{3}$ and/or protein level $>0.45 \mathrm{~g} / \mathrm{L}$ in cerebrospinal fluid (CSF), without bacteria/virus or tumor cells detection; (3) normal brain/spine imaging. Patients were included in this study if followed by a neurologist for at least 6 months after meningitis occurrence. The decision of ICI reintroduction was made on a case-by-case basis.

We collected patients demographics and ir-meningitis characteristics. IrAEs were defined using the National Cancer Institute Common Terminology Criteria for Adverse Events, V.4.03. ${ }^{9}$ Duration of corticosteroids was collected, and patients were considered 'off steroids' when hydrocortisone equivalent dose was $\leq 30 \mathrm{mg} /$ day. We also collected tumor evaluations according to the ir-response criteria ${ }^{10}$ at 3 months after the ICI readministration and at the latest follow-up.

\section{RESULTS}

We, here, report seven consecutive cases of ir-meningitis. Table 1 summarizes demographic and clinical characteristics of patients. Median delay of meningitis onset after the first dose of ICI was 9 days (range: 6-95 days). CSF study displayed lymphocytic meningitis in six out of seven patients, and an isolated high protein level in patient 5 , but lumbar puncture was realized 45 days after the onset of neurological symptoms in this patient. CSF microbiological studies were negatives in all patients and no evidence of tumor meningitis was found in CFS study or brain and spine MRI. MRI did not find any signs of myelitis nor encephalitis, and therefore, a diagnosis of isolated ir-meningitis was made.

After diagnosis of ir-meningitis, a steroid treatment (prednisone $1 \mathrm{mg} / \mathrm{kg}$ ) was introduced in patients 1,2 , 4 and 6 (all with irAEs- $\mathrm{N} \geq$ grade 2 ), allowing a complete clinical recovery within 2 weeks. After 1-2 weeks of full dose, corticosteroids were gradually tapered until discontinuation after 6 weeks. The other three patients (all with grade 1 AEs) spontaneously improved within 3 weeks (table 2).

Given the favorable outcome of ir-meningitis, ICI treatment was reintroduced in four patients (cases 2, 3, $5,7)$ after 4-54 days from irAE-N. For the other three patients, despite a quick recovery of meningitis, ICI was not resumed immediately because of the high grade of $\mathrm{nAE}$ (grade 3 ) in patient 1 , and of multiple co-occurring non neurological irAEs in patients 4 and 6 . These patients were followed by whole body imaging every 3 months and ICIs were reintroduced at time of disease progression.

The rechallenge was well tolerated in six out of seven cases: no meningitis nor other irAEs occurred. Patient 3 developed a severe interstitial lung disease, without meningitis recurrence, leading to permanent discontinuation of ICI treatment (table 3 ). Table 3 shows the cancer status at 3 months from the rechallenge of ICIs and at the latest follow-up.

\section{DISCUSSION}

A broad spectrum of neurological irAEs has been described in the literature, potentially involving all areas of the central and peripheral nervous system. ${ }^{211}$ Cases of ir-meningitis have been less frequently reported. However, their frequency is likely underestimated because their presentation can be paucisymptomatic. The occurrence of an unusual headache during ICI treatment should raise the suspicion of meningitis and lead to appropriate 
Table 2 Characteristics of ir-meningitis and management with steroids

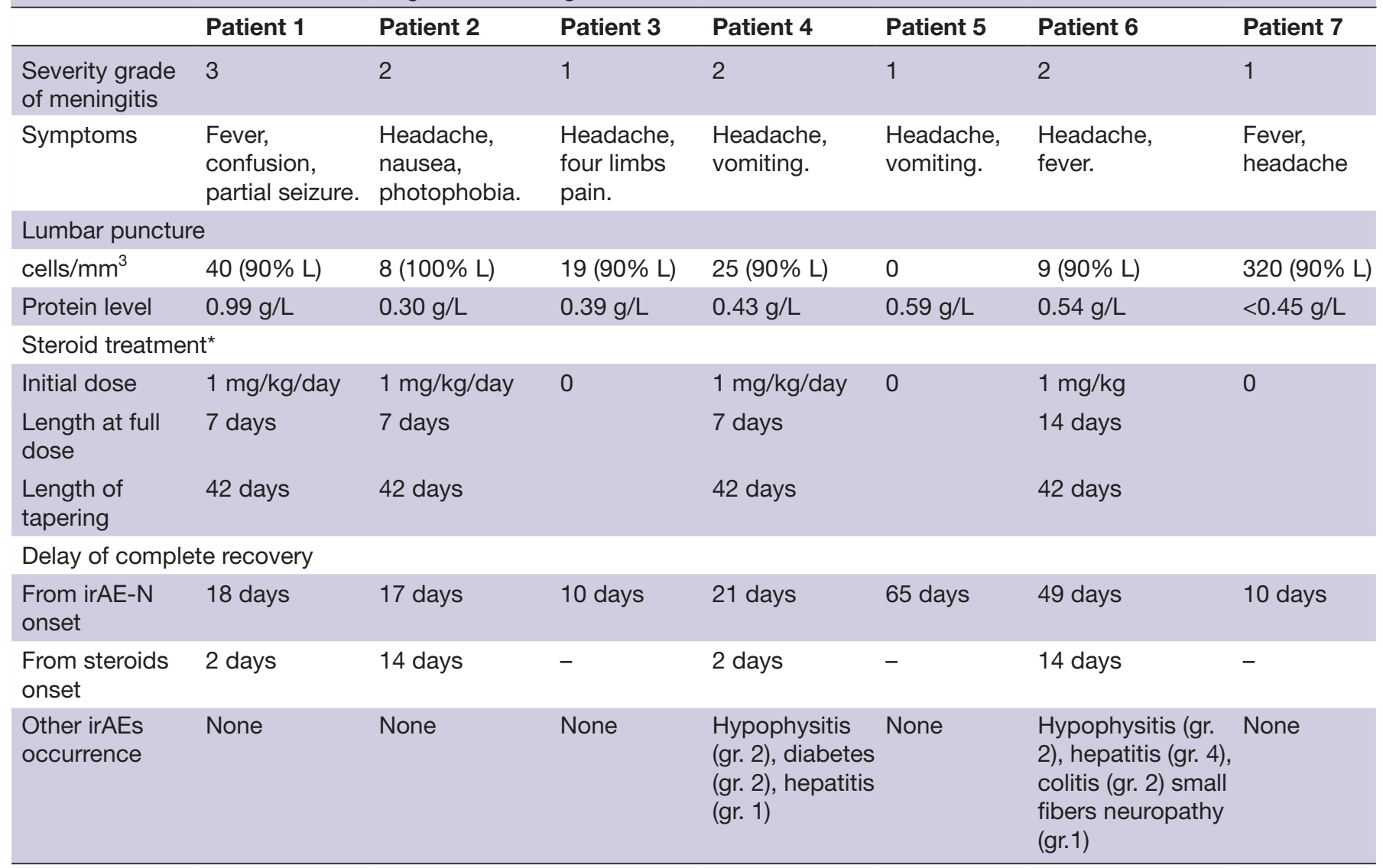

*Prednisone equivalent doses.

irAE, immune-related adverse event; irAE-N, neurological immune-related adverse event; L, lymphocytes.

investigations. Notably, differential diagnosis with bacterial/viral meningitis and meningeal carcinomatosis must be considered in first place, hence lumbar puncture and brain/spine MRI with and without contrast generally lead to the correct diagnosis.

As reported for other irAEs-N, we did not observe any exclusive association between ir-meningitis and a class of ICIs. ${ }^{28}$ Clinical signs of meningitis occurred early with a median delay of 9 days after the ICI onset and a median number of ICI cycles of 2, compared with 6 weeks and three cycles observed in all kinds of irAEs-N respectively. ${ }^{28}$ Ir-meningitis had a favorable evolution with a fast and full recovery in all patients. According to published recommendations, ${ }^{12}$ steroid treatment was introduced in more severe cases (grade $\geq 2$ ) and maintained at full dose (prednisone $1 \mathrm{mg} / \mathrm{kg} /$ day) for one or 2 weeks depending on the clinical recovery of meningitis and then tapered over 6 weeks given the half-life of ICI drugs.

The safety of ICI reintroduction after an irAE is still a matter of debate. Some studies showed a quite poor tolerance of resuming ICI after a severe irAE, reporting an occurrence of the same or a distinct AE in $40 \%-55 \%$ of patients. ${ }^{5-7}$ The risk of irAEs-N recurrence is likely similar to other ir-AEs, but, very few cases of reintroduction of ICIs after an irAE-N have been reported so far, probably because of concerns on potential severity and life-threatening risk associated to irAEs-N. Dubey et al reported a series of 10 patients retreated with ICIs after a severe irAEs-N. The irAE-N recurrence rate was $60 \%$ and the authors suggested a correlation with a short steroid treatment (less than 2 weeks) after the initial AE in these patients. $^{8}$

Only few cases of ICI rechallenge after an ir-meningitis are reported in literature. Spain et al reported a melanoma patient with meningitis associated with ir-hepatitis. The rechallenge with the same regimen resulted in severe ir-colitis. ${ }^{13}$ Fellner et al reported another case of reintroduction of ICIs after meningitis related to ipilimumab-nivolumab combination therapy. In this case, only nivolumab was resumed, with a good tolerance. ${ }^{14}$ In both cases, ICI drugs were reintroduced at the moment of cancer recurrence according to checkmate-067 trial results, in which $68 \%$ of patients who discontinued ICI treatment due to toxicity experienced a long response (median time of 13 months). ${ }^{15}$

In our series of seven consecutive patients, ICI treatment was early reintroduced in four patients (all with irAE-N grade $\leq 2$ ), as soon as the meningitis symptoms had completely recovered. Tolerance of reintroduction was good in three out of four patients. One patient 
Table 3 Tolerance of $\mathrm{ICl}$ reintroduction

\begin{tabular}{|c|c|c|c|c|c|c|c|}
\hline & Patient 1 & Patient 2 & Patient 3 & Patient 4 & Patient 5 & Patient 6 & Patient 7 \\
\hline $\begin{array}{l}\text { Delay of resumption } \\
\text { of } \mathrm{ICl} \text { after } \\
\text { meningitis } \\
\text { (days) }\end{array}$ & 373 & 54 & 24 & 118 & $\begin{array}{l}4 \\
\text { (No ICl } \\
\text { discontinuation) }\end{array}$ & 126 & 19 \\
\hline $\begin{array}{l}\mathrm{ICI} \text { regimen at the } \\
\text { rechallenge }\end{array}$ & $\begin{array}{l}\text { Ipilimumab } \\
1 \mathrm{mg} / \mathrm{kg} \\
+ \text { nivolumab } \\
3 \mathrm{mg} / \mathrm{kg}\end{array}$ & $\begin{array}{l}\text { Ipilimumab } \\
1 \mathrm{mg} / \mathrm{kg} \\
+ \text { nivolumab } \\
3 \mathrm{mg} / \mathrm{kg}\end{array}$ & $\begin{array}{l}\text { Spartalizumab } \\
400 \mathrm{mg}\end{array}$ & $\begin{array}{l}\text { Nivolumab } \\
3 \mathrm{mg} / \mathrm{kg}\end{array}$ & $\begin{array}{l}\text { Nivolumab } \\
3 \mathrm{mg} / \mathrm{kg}\end{array}$ & $\begin{array}{l}\text { Spartalizumab } \\
400 \mathrm{mg} \\
\text { +ribociclib } \\
600 \mathrm{mg} / \text { day }\end{array}$ & $\begin{array}{l}\text { Nivolumab } \\
3 \mathrm{mg} / \mathrm{kg}\end{array}$ \\
\hline $\begin{array}{l}\text { Steroid treatment } \\
\text { at the time of } \mathrm{ICI} \\
\text { resumption* }\end{array}$ & $\begin{array}{l}0.5 \mathrm{mg} / \mathrm{kg} / \\
\text { day }\end{array}$ & 0 & 0 & 0 & 0 & 0 & 0 \\
\hline $\begin{array}{l}\text { Meningitis } \\
\text { recurrence }\end{array}$ & No & No & No & No & No & No & No \\
\hline $\begin{array}{l}\text { Cancer status at } \\
\text { latest follow-up } \\
\text { (months from } \\
\text { rechallenge) }\end{array}$ & $\begin{array}{l}\text { Death caused } \\
\text { by cancer } \\
\text { progression }\end{array}$ & $\begin{array}{l}\text { Maintained } \\
\text { CR } \\
\text { (32 months) }\end{array}$ & $\begin{array}{l}\text { Maintained PR } \\
\text { (25 months) }\end{array}$ & $\begin{array}{l}\text { Death caused } \\
\text { by cancer } \\
\text { progression }\end{array}$ & $\begin{array}{l}\text { Maintained PR } \\
\text { (6 months) }\end{array}$ & $\begin{array}{l}\text { Death caused } \\
\text { by cancer } \\
\text { progression }\end{array}$ & $\begin{array}{l}\text { Maintained } \\
\text { PR } \\
\text { (17 months) }\end{array}$ \\
\hline
\end{tabular}

${ }^{*}$ Prednisone equivalent doses.

$\mathrm{CR}$, complete response; ICl, immune-checkpoint inhibitor; irAE, immune-related adverse event; PD, progression disease; PR, partial response.

developed a severe non-neurological irAE (interstitial lung disease) leading to permanent discontinuation of ICI treatment. In the three other cases, ICI reintroduction was differed at the time of disease progression since ir-meningitis was more severe or associated with other irAEs. In cases of multiple irAEs, dual therapy was shifted to anti-PD1 monotherapy regimen. The reintroduction was well tolerated in all cases: no patients experienced a recurrent or new irAE.

\section{CONCLUSIONS}

Cases of meningitis related to ICIs are poorly described in literature. In our cases, the clinical course was favorable and steroids were not always required. In case of isolated ir-meningitis, an early reintroduction of ICI treatment at the same regimen appears to be safe, even in case of combination therapy (anti-CTLA-4/PD-1). On the contrary, a longer discontinuation of ICI drug (until disease progression) and a regimen shift from dual to monotherapy is recommended in case of multiple irAEs. We are aware that our study has some limitations since only one patient experienced a high grade ir-meningitis. A careful analysis of the risk/benefit ratio should be done on a case-by-case basis.

Acknowledgements The authors thank MelBase biobank coordination team for technical support and medical data and PATIO group for the constructive exchanges.
Contributors SC conceptualized the study, collected and analyzed data, and wrote the preliminary version of the paper. AFC conceptualized the study and wrote the preliminary version of the paper. PT, SG, RU, CB, LSV, JM, CLh, CLe and $\mathrm{BB}$ contributed to the collection of patient data. All authors participated in critical review and revision of the final manuscript.

Funding The authors have not declared a specific grant for this research from any funding agency in the public, commercial or not-for-profit sectors.

Competing interests BB is a consultor for BMS, MSD and Pierre Fabre; CLh received grants or honoraria from Roche, BMS, MSD, GSK, Novartis and Amgen; $\mathrm{AFC}$ is a consultor for BMS.

Patient consent for publication Not required.

Ethics approval MelBase protocol was approved by the French ethics committee (CPP Ile-de-france XI, no 12027, 2012).

Provenance and peer review Not commissioned; externally peer reviewed.

Data availability statement All data relevant to the study are included in the article.

Open access This is an open access article distributed in accordance with the Creative Commons Attribution Non Commercial (CC BY-NC 4.0) license, which permits others to distribute, remix, adapt, build upon this work non-commercially, and license their derivative works on different terms, provided the original work is properly cited, appropriate credit is given, any changes made indicated, and the use is non-commercial. See http://creativecommons.org/licenses/by-nc/4.0/.

\section{ORCID iD}

Stefania Cuzzubbo http://orcid.org/0000-0003-0288-4607

\section{REFERENCES}

1 Baroudjian B, Arangalage D, Cuzzubbo S, et al. Management of immune-related adverse events resulting from immune checkpoint blockade. Expert Rev Anticancer Ther 2019;19:209-22. 
2 Cuzzubbo S, Javeri F, Tissier M, et al. Neurological adverse events associated with immune checkpoint inhibitors: review of the literature. Eur J Cancer 2017;73:1-8.

3 Cuzzubbo S, Belin C, Chouahnia K, et al. Assessing cognitive function in patients treated with immune checkpoint inhibitors: a feasibility study. Psychooncology 2018;27:1861-4.

4 Brahmer JR, Lacchetti C, Schneider BJ, et al. Management of immune-related adverse events in patients treated with immune checkpoint inhibitor therapy: American Society of clinical oncology clinical practice guideline. JCO 2018;36:1714-68.

5 Pollack MH, Betof A, Dearden $\mathrm{H}$, et al. Safety of resuming antiPD-1 in patients with immune-related adverse events (irAEs) during combined anti-CTLA-4 and anti-PD1 in metastatic melanoma. Ann Oncol 2018;29:250-5

6 Simonaggio A, Michot JM, Voisin AL, et al. Evaluation of readministration of immune checkpoint inhibitors after immunerelated adverse events in patients with cancer. JAMA Oncol 2019;5:1310-7.

7 Santini FC, Rizvi H, Plodkowski AJ, et al. Safety and efficacy of retreating with immunotherapy after immune-related adverse events in patients with NSCLC. Cancer Immunol Res 2018;6:1093-9.

8 Dubey D, David WS, Reynolds KL, et al. Severe neurological toxicity of immune checkpoint inhibitors: growing spectrum. Ann Neurol 2020;87:659-69.
9 Puzanov I, Diab A, Abdallah K, et al. Managing toxicities associated with immune checkpoint inhibitors: consensus recommendations from the Society for immunotherapy of cancer (SITC) toxicity management Working group. J Immunother Cancer 2017;5:95.

10 Wolchok JD, Hoos A, O'Day S, et al. Guidelines for the evaluation of immune therapy activity in solid tumors: immune-related response criteria. Clin Cancer Res 2009;15:7412-20.

11 Astaras C, de Micheli R, Moura B, et al. Neurological adverse events associated with immune checkpoint inhibitors: diagnosis and management. Curr Neurol Neurosci Rep 2018;18:3.

12 Spain L, Tippu Z, Larkin JM, et al. How we treat neurological toxicity from immune checkpoint inhibitors. ESMO Open 2019;4:e000540.

13 Spain L, Walls G, Messiou C, et al. Efficacy and toxicity of rechallenge with combination immune checkpoint blockade in metastatic melanoma: a case series. Cancer Immunol Immunother 2017;66:113-7.

14 Fellner A, Makranz C, Lotem M, et al. Neurologic complications of immune checkpoint inhibitors. J Neurooncol 2018;137:601-9.

15 Larkin J, Chiarion-Sileni V, Gonzalez R, et al. Combined nivolumab and ipilimumab or monotherapy in untreated melanoma. N Engl $J$ Med 2015;373:23-34. 